\title{
Modeling neural differentiation on micropatterned substrates coated with neural matrix components
}

\author{
Patricia García-Parra ${ }^{1,2,3}$, Fabio Cavaliere ${ }^{4}$, Marcos Maroto ${ }^{5}$, Leire Bilbao ${ }^{1}$, Isabel Obieta ${ }^{1}$, \\ Adolfo López de Munain ${ }^{2}$, José Iñaki Álava ${ }^{1 \dagger}$ and Ander Izeta ${ }^{3 *}$ \\ ${ }^{1}$ Biomaterials-Tissue Engineering Unit, Tecnalia Research and Innovation, San Sebastian, Spain \\ 2 Department of Neuroscience and CIBERNED, Instituto Biodonostia, Hospital Universitario Donostia, San Sebastian, Spain \\ ${ }^{3}$ Department of Bioengineering, Tissue Engineering Laboratory, Instituto Biodonostia, Hospital Universitario Donostia, San Sebastian, Spain \\ ${ }^{4}$ Department of Neuroscience and CIBERNED, Neurotek-UPV/EHU, Zamudio, Spain \\ ${ }^{5}$ Facultad de Medicina, Instituto Teófilo Hernando, Universidad Autónoma de Madrid, Madrid, Spain
}

Edited by:

Afsaneh Gaillard, University of

Poitiers, France

Reviewed by:

Mohamed Jaber, University of

Poitiers, France

Afsaneh Gaillard, University of

Poitiers, France

Jung Yul Lim, University of

Nebraska-Lincoln, USA

\section{*Correspondence:}

Ander Izeta, Instituto Biodonostia,

Hospital Universitario Donostia,

Paseo Dr. Begiristain s/n, 20014

San Sebastian, Spain.

e-mail:

ander.izetapermisan@osakidetza.net

${ }^{\dagger}$ Present Address:

Basque Culinary Center R\&D,

San Sebastian, Spain.
Topographical and biochemical characteristics of the substrate are critical for neuronal differentiation including axonal outgrowth and regeneration of neural circuits in vivo. Contact stimuli and signaling molecules allow neurons to develop and stabilize synaptic contacts. Here we present the development, characterization and functional validation of a new polymeric support able to induce neuronal differentiation in both PC12 cell line and adult primary skin-derived precursor cells (SKPs) in vitro. By combining a photolithographic technique with use of neural extracellular matrix (ECM) as a substrate, a biocompatible and efficient microenvironment for neuronal differentiation was developed.

Keywords: micropatterning, photolithography, ECM (extracellular matrix), progenitor cell, neural differentiation, nerve tissue engineering

\section{INTRODUCTION}

The interface of biomaterials and stem cells may provide new strategies for reconnecting severed nerve pathways in the nervous system after injury (Dalton and Mey, 2009; Orive et al., 2009). The ability to recreate the cellular microenvironment is also important to understand cell behavior and functionality in vitro (Schenke-Layland et al., 2009). In vivo, the existence of an organized extracellular matrix (ECM) promotes cell adhesion, differentiation and proliferation and hence maintenance of tissue homeostasis. In the nervous system, axonal pathfinding and regeneration are mediated by individual and/or synergistic stimulatory and inhibitory cues (Li et al., 2008). In fact, substrate discontinuities generate an orientation in cell locomotion known as "contact guidance", which is ubiquitously found in development, growth, and regeneration of nerves (Corey and Feldman, 2003). In contrast, random spatial distribution and overlap of neurites is often found in standard cell culture.

A promising approach in manipulating the cellular microenvironment is the use of micromanufacturing technologies such as microcontact printing or photolithography, because of comparable physical dimensions to cellular constructs (Hook et al., 2009). Among others, micropatterning has been recently applied to human neural progenitor cells grown on polystyrene coated with entactin, collagen, and laminin (Blong et al., 2010), to spiral ganglion neurons and Schwann cells patterned on methacrylate
(Clarke et al., 2011), to dissociated dorsal root ganglion neurons seeded onto laminin- and fibronectin-spotted surfaces (Fereol et al., 2011), primary adult human neural stem cells (Beduer et al., 2012) and differentiated human SH-SY5Y neuron-like cells (Hardelauf et al., 2011) grown on polydimethylsiloxane (PDMS) membranes, hippocampal neurons grown on poly-Dlysine micron-wide lines patterned onto a poly(ethylene glycol) (PEG) monolayer (Wissner-Gross et al., 2011) and dissociated central nervous system neurons (Hellman et al., 2010; Takayama et al., 2011), embryonic stem cell-derived motor neurons (Shi et al., 2010), and primary cortical neurons (Kunze et al., 2011) seeded into diverse microfluidic cell culture settings.

Although cells may adhere to a variety of untreated polymeric surfaces, several synthetic polymers (e.g., PEG) do not permit cell attachment in the absence of coating. For in vitro neural differentiation, polylysine and polyornithine have been widely used as adhesive treatments for the substrate. However neural ECM is far more complex in terms of structure, organization, and different constituent parts in vivo. To improve in vitro neural differentiation, we mimicked neural ECM by using the following substrate: (1) a commercially available soluble basement membrane extract, purified from mouse sarcoma $\left(\mathrm{Cultrex}^{\circledR}\right)$ that contains laminin, collagen type IV, heparan sulphate, entactin, and growth factors (Kleinman, 2001; Arnaoutova et al., 2012); (2) hyaluronic acid (Turley et al., 2002), and (3) netrins, i.e., 
laminin-related neuropeptides involved in neurite outgrowth and axonal guidance (Rajasekharan and Kennedy, 2009; McCormick and Leipzig, 2012). Similar basement membrane-based substrates have recently been reported for in vitro neural engineering, specifically for Schwann cells (Dewitt et al., 2009) and embryonic stem cell-derived neural precursor cells (Uemura et al., 2010).

The presence of collagen, laminin, entactin, and certain proteoglycans in the basal composition of ECM provides the signal that cells need to be anchored to the substrate and start differentiation. In particular, hyaluronic acid is an anionic polysaccharide that forms electrostatic complexes with cationic molecules such as collagen or polylysine (Pan et al., 2009); hence collagen ionic adsorption alters the cell repulsion that is inherent to hyaluronic acid (Takahashi et al., 2009), allowing the incorporation of this molecule into the matrix (Wang and Spector, 2009). On the other hand, netrins act as cellular and neurite-chemoattractant factors, as it occurs in the developing neural tissue (O'Donnell et al., 2009). In addition to its composition, thickness of the matrix is also fundamental in cell differentiation as recently demonstrated (Leipzig and Shoichet, 2009).

To model in vitro differentiation, we used both $\mathrm{PC} 12$ cell line and primary skin-derived neural precursor cells. PC12 cells have been widely used in both neurobiological and neurotoxicological studies as an in vitro model for neuronal differentiation (Das et al., 2004). The cell line originated clonally from rat pheochromocytoma. In response to nerve growth factor (NGF), PC12 cells undergo a dramatic change of phenotype and acquire properties of sympathetic neurons. NGF-treated PC12 cells cease proliferation, extend neurites and become electrically excitable (Greene and Tischler, 1976). Importantly, these cells have already been shown to grow and differentiate in micropatterns of different kinds (Foley et al., 2005; Ferrari et al., 2010; Yang et al., 2011).

Starting up from a protocol to isolate and culture CNS stem cells (Reynolds and Weiss, 1992), Miller and colleagues isolated skin-derived precursor cells (SKPs) from the dermis (Toma et al., 2001). These precursor cells have the potential to generate progeny of the neuronal and glial lineages, amongst other cell types (Fernandes et al., 2008; Hunt et al., 2009). Importantly, dopaminergic neurons have been generated in vitro from SKPs and transplanted into the striata of a Parkinson disease (PD) rat model (Kubo et al., 2009; Higashida et al., 2010). Although these recent findings will need validation by independent research groups, they hint the potential to isolate autologous dermal precursor cells and, after in vitro differentiation to the desired lineage, apply the differentiated neurons for cell replacement therapies of Parkinson's disease.

In the current study, we hypothesized that combining the topography of a micropatterned substrate by photolithographic technique- with the signals of neural matrix components would supply the cells the appropriate environment and signal cues for neural differentiation. We chose PC12 cells as a widely used cell model to study the biocompatibility and neuronal differentiation potential of our experimental set up, and observed neurite outgrowth in the absence of added NGF. Finally, we confirmed the enhancement of neuronal differentiation with primary SKPs isolated from adult rat skin. Taking into account the aforementioned studies on derivation of dopaminergic neurons from SKPs, our work might add on the necessary strategies to improve differentiation of neuronal precursor cells into substantia nigra dopaminergic neurons (Gaillard and Jaber, 2011).

\section{MATERIALS AND METHODS GENERATION OF MICROPATTERNED SUBSTRATES USING PHOTOLITHOGRAPHY}

A mask template was made with a pattern consisting of a repetition of squares and rectangles of $300 \times 300 \mu \mathrm{m}$ and $300 \times$ $400 \mu \mathrm{m}$, respectively, situated between interconnected channels of $200 \times 200 \mu \mathrm{m}$ (Figures 1A,B). Micropatterned substrates were manufactured using standard photolithographic techniques. Glass coverslips (Menzel-Gläser, $24 \times 24 \mathrm{~mm}$ ) were chemically etched with a 1:2(v/v) solution of hydrofluoric acid (Panreac) for $5 \mathrm{~min}$ in order to improve the adhesion of the photoresist to glass. Briefly, SU-8 2,100 photoresist (MicroChem Inc.) was spin-coated in an EVG-101 machine onto etched coverslip surfaces ( $1 \mathrm{ml} /$ coverslip). Spinning conditions of 4,000 rpm and $1,000 \mathrm{rpm} / \mathrm{s}$ for $60 \mathrm{~s}$ were used in order to uniformly coat the glass coverslips with a layer of photoresist (approximately $15 \mu \mathrm{m}$ thick). Coverslips were pre-baked previous to the UV (365 nm) exposure, in an EVG-620 mask aligner for $20 \mathrm{~s}$; and post-baked, developed and thoroughly cleaned in isopropyl alcohol (Sigma). Finally, coverslips were baked on a hot plate at $150^{\circ} \mathrm{C}$ for approximately $30 \mathrm{~min}$ in order to remove any traces of volatile chemicals still present in the layer of SU-8.

\section{NEURAL-LIKE EXTRACELLULAR MATRIX (ECM) DEPOSITION}

Micropatterned coverslips were cleaned with distilled water, sterilized by exposition to UV light for $30 \mathrm{~min}$ and incubated with a solution of Cultrex ${ }^{\circledR}$ basement membrane extract (without phenol red, R\&D), hyaluronan of low (31 kDa, HLMW) or high $(980 \mathrm{kDa}, \mathrm{HHMW})$ molecular weight (R\&D), Netrin-Gla and Netrin-4 (R\&D) in phosphate-buffered saline (PBS, Gibco). In order to polymerize and adsorb the matrix on the exposed glass surface they were kept for $24 \mathrm{~h}$ at $37^{\circ} \mathrm{C}$ in sterile conditions. Next, excess PBS was eliminated and coverslips left to dry up for $1 \mathrm{~h}$ under laminar flow and UV light. Prior to cell seeding, polymeric substrates were sterilized by exposition to UV light for $30 \mathrm{~min}$ in a tissue culture hood. Excess matrix deposited over the "peaks" was eliminated by incubation with culture medium for $24-48 \mathrm{~h}$ at $37^{\circ} \mathrm{C}$.

\section{MICRO AND NANO-CHARACTERIZATION OF ECM}

The ECM topography was characterized by Atomic Force Microscopy (AFM) by using a Digital Instruments Nanoscope ${ }^{\circledR}$ IIIA. Samples were fixed with Vitrosec ${ }^{\circledR} 70$ (Panreac) for 20 min. Measurements were acquired in tapping mode using a silicon tip and the resonance frequency set at $300 \mathrm{KHz}$. Topography measurements were performed both in dry and wet conditions. AFM data were analyzed with Multimode ${ }^{\circledR}$ SPM. For Scanning Electron Microscopy (SEM), polymeric substrates with or without cells were fixed with Vitrosec ${ }^{\circledR} 70$ for 20 min and stained with Coomassie brilliant blue R-250 staining solution (Bio-Rad) for $5 \mathrm{~min}$ at room temperature. Excess staining solution was removed with water. Samples were dried and mounted onto aluminium 


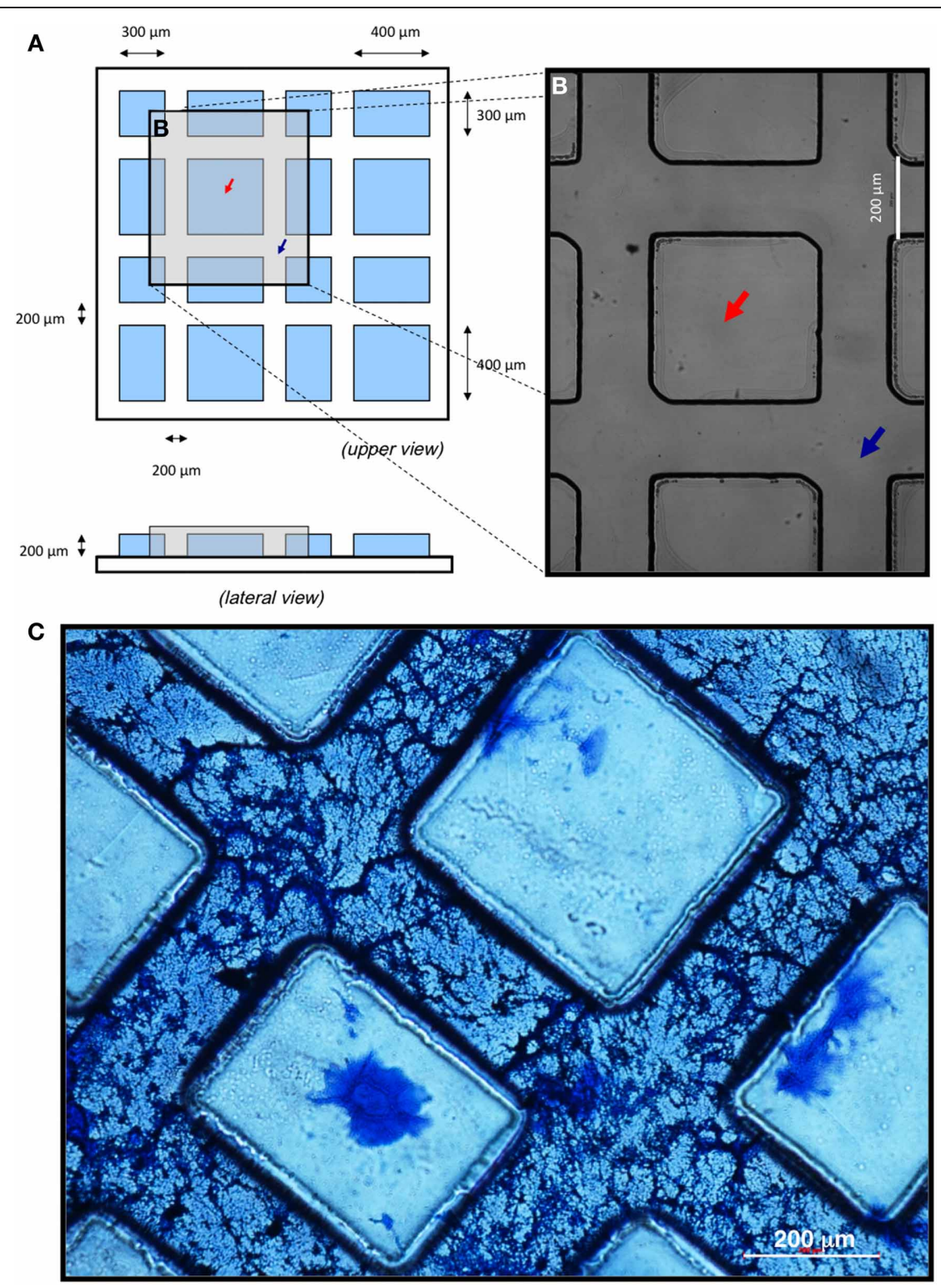

FIGURE 1 | Surface patterning of coverslips using photolithographic technique and coating with neural ECM. (A-B) Cartoon depicting the upper and lateral views of the micropatterned substrate (A) and optical microscopy image after conclusion of the photolithographic process, when "peaks" (red arrows) and "valleys" (blue arrows) were formed (B).
(C) Polymerization and penetration of the ECM into micropatterned substrates. Hyaluronic acid of low molecular weight (HLMW) allowed for dispersion of the matrix along the valleys of the patterned surface. A 1:3 dilution of the ECM with HLMW achieved the desired fibrous structure. Scale bars, $200 \mu \mathrm{m}$. disks and coated with gold-argon. Imaging was performed on a JEOL JSM-5910-LV SEM using a $20 \mathrm{kV}$ acceleration voltage. Samples were analyzed by an INCA-300 energy dispersed system (EDS) coupled to the microscope.

\section{PC12 CELL LINE MAINTENANCE AND DIFFERENTIATION}

Rat PC12 cells (CRL-1721, ATCC) were maintained in Ham's F12 medium modified by Kaighn (F12K, Gibco) and supplemented with 2.5\% fetal bovine serum (ATCC), 15\% horse serum (ATCC) and $1 \%$ penicillin/streptomycin (P/S, Sigma). The differentiation of PC12 cells on micropatterned substrates was carried out for
7 days in the same maintenance medium (without NGF) at a cell density of 2,500-120,000 cells/ml.

\section{ISOLATION, LABELING, AND DIFFERENTIATION OF ADULT RAT SKPS}

All experiments were carried out in accordance with the guidelines established by the National Council on Animal Care. SKPs were isolated from the dorsal skin of adult Wistar female rats modifying previously described protocols (Biernaskie et al., 2006). Five $\mathrm{cm}^{2}$ of rat dorsal skin were incubated for $30 \mathrm{~min}$ on ice in Hank's balanced salt solution (HBSS, Gibco), supplemented with $2 \% \mathrm{P} / \mathrm{S}$ and $2 \%$ Fungizone $^{\mathrm{TM}}$ (Gibco). Skin 
was cut into $2 \mathrm{~mm}^{2}$ pieces and incubated in collagenase type IA solution $(2 \mathrm{mg} / \mathrm{ml} ; 650 \mathrm{CDU} / \mathrm{mg}$, Sigma $)$ for $3 \mathrm{~h}$ at $37^{\circ} \mathrm{C}$ under gentle shaking. Undigested skin was mechanically dissociated by vigorous pipetting. The resulting cell suspension was filtered through $40 \mu \mathrm{m}$ nylon cell strainers (BD), centrifuged at $1,500 \mathrm{rpm}$ for $5 \mathrm{~min}$, and resuspended in Neurobasal ${ }^{\mathrm{TM}}$ A medium (Gibco) supplemented with 2\% B27 Supplement (Gibco), 1\% L-glutamine solution 200mM (Sigma), and 1\% P/S. Every 2 days, the medium was supplemented with $20 \mathrm{ng} / \mathrm{ml}$ epidermal growth factor (EGF, R\&D), $40 \mathrm{ng} / \mathrm{ml}$ fibroblast growth factor basic (FGF2, R\&D) and 2\% low serum growth supplement (LSGS, Gibco). Under these culture conditions, neurosphere-like structures [here dubbed "dermospheres" (Gago et al., 2009)] were formed within $48 \mathrm{~h}$ culture. Cells were gently resuspended in medium before plating onto the ECM substrate. The differentiation of SKPs (10 dermospheres/coverslip) was carried out in the same maintenance medium plus with $1 \%$ N2 Supplement (Gibco) and 10\% fetal bovine serum (ATCC). Every 2 days, half medium was replaced and supplemented with $50 \mathrm{ng} / \mathrm{ml}$ nerve growth factor $\beta$ (NGF $\beta$, Sigma), $50 \mathrm{ng} / \mathrm{ml}$ brain-derived neurotrophic factor (BDNF, Sigma), $200 \mathrm{ng} / \mathrm{ml}$ Sonic hedgehog (SHH, R\&D), and $200 \mathrm{ng} / \mathrm{ml}$ fibroblast growth factor $8 \mathrm{~b}$ (FGF8b, R\&D). For quantitative assessment of differentiation, at least ten different fields out of three independent experiments were quantified.

\section{MORPHOMETRIC ANALYSES, IMMUNOFLUORESCENCE AND CONFOCAL MICROSCOPY}

For morphometric analyses of differentiated PC12 cells, digitized images of cells stained with May-Grünwald's eosin methylene blue solution (Merck) or with Bodian's silver proteinate (Sigma) were taken with a DSFil camera attached to an Eclipse TS100 microscope (Nikon). Images were analyzed with NIS-Elements F2.30 software (Nikon). Total neurons, neurites by neuron and apparently connected neurites by neuron were quantified on each condition. At least ten different fields out of three independent experiments were quantified. After 20 days in neuronal differentiation conditions, rat SKPs were washed with 1X PBS and fixed in 4\% paraformaldehyde aqueous solution (Electron Microscopy Sciences) for $20 \mathrm{~min}$ at room temperature. Cells were washed in PBS, permeabilized for $1 \mathrm{~h}$ in $0.3 \%$ Triton ${ }^{\circledR} \mathrm{X}-100$ (Sigma) in PBS (PBS-T) and 5\% normal donkey serum (Sigma). Cells were incubated with the appropriate primary antibody diluted in PBS-T for $2 \mathrm{~h}$ at room temperature. Primary antibodies used were anti-neurofilament light (NFL; used at 1:100 dilution; Cell Signaling Technology \#2835), anti-tyrosine hydroxilase (TH; 1:1,000; Millipore \#AB152), anti-Nestin (1:200; Millipore \#MAB353), anti- $\beta$ III-tubulin (1:10, R\&D \#964673) and anti- $\alpha$ smooth muscle actin ( $\alpha$-SMA; 1:500; Sigma \#A2547). Next, cells were 1X PBS washed 3 times ( 5 min each) and incubated with the appropriate secondary antibody diluted in PBS-T for $1 \mathrm{~h}$ at room temperature. Secondary antibodies used were goat anti-mouse Alexa Fluor ${ }^{\circledR} 488$ (Invitrogen; 1:1,000) and donkey anti-rabbit Alexa Fluor ${ }^{\circledR} 546$ (1:1,000; Invitrogen). Prior to mounting in Mowiol ${ }^{\circledR}$ mounting medium (Fluka), cells were incubated with $10 \mu \mathrm{g} / \mathrm{ml}$ Hoechst 33258 (Sigma) for $5 \mathrm{~min}$ and washed with distilled water. Images were obtained by using a Zeiss LSM 510 microscope coupled to Zeiss Axion camera and analyzed by using Zeiss ZEN image analysis software (2008; SP1.1).

\section{STATISTICAL ANALYSES}

Data are expressed as means \pm standard deviations of the number of independent experiments. One-Way ANOVA and Bonferroni post-test analyses were performed with GraphPad Prism 5.04 for Windows software.

\section{RESULTS}

\section{DEVELOPMENT AND CHARACTERIZATION OF NEURAL ECM} DEPOSITION ON MICROPATTERNED SUBSTRATES

In order to generate patterned in vitro neuronal differentiation conditions, micropatterns were reproducibly manufactured by photolithography on glass coverslips, as detailed in Materials and Methods. To create interconnected channels large enough to accommodate several aligned and interconnected neuronal cells, surface microgeometry was designed as hydrophobic "peaks" delineating $200 \mu \mathrm{m}$ wide, interconnected "valleys" (Figures 1A,B).

To attain preferential deposition of neural ECM on the valleys and to generate a three-dimensional structure suitable for cell culture, several combinations of basal membrane and hyaluronic acid were assayed (not shown). Coomassie blue staining of matrix proteins showed that high molecular weight hyaluronic acid (HHMW; both diluted and undiluted) prevented proper polymerization of the matrix. In contrast, low molecular weight hyaluronic acid (HLMW) dispersed the matrix along the valleys of the patterned surface, originating an adequate and homogeneous fibrous structure only when ECM was diluted 1:3 (Figure 1C). Thus, a 1:3 dilution of soluble basal membrane extract mixed with HLMW was chosen for proper polymerization of the matrix, showing both cell penetrating capacity throughout the patterned substrate and the desired fibrous structure for cell growth.

Micro- and nanostructural morphology of the matrix on the patterned substrates was then characterized by SEM and AFM, respectively (Figure 2A). Deposited proteins were stained with Coomassie blue (Figure 2B) and coated with a thin layer of evaporated gold to allow correct display of the matrix structure by SEM (Figure 2C). As shown in Figures 2D-G, the matrix presented a homogeneous fibrous network structure in which pores of different sizes were seen. To characterize the matrix at the nanometric scale, patterned substrates were analyzed by AFM (Figures $2 \mathbf{H}, \mathbf{I})$. An average surface roughness $\left(\mathrm{R}_{\mathrm{ms}}\right)$ of $125.91 \mathrm{~nm}$ was found in dry conditions. When the samples were hydrated by incubation in distilled water, average surface roughness $\left(\mathrm{R}_{\mathrm{ms}}\right)$ increased to $235.63 \mathrm{~nm}$, possibly due to the hydration capacity conferred to ECM by hyaluronic acid.

\section{DIFFERENTIATION OF PC12 CELLS IN THE ABSENCE OF NGF GENERATES TYROSINE HYDROXILASE (TH)-POSITIVE NEURONS}

To ascertain the effect of the substrate on neuronal differentiation and neurite outgrowth, PC12 cells were cultured in the absence of the differentiation-inducing factor NGF, which was purposedly excluded to isolate the effect of the matrix on PC12 differentiation from other external clues. 

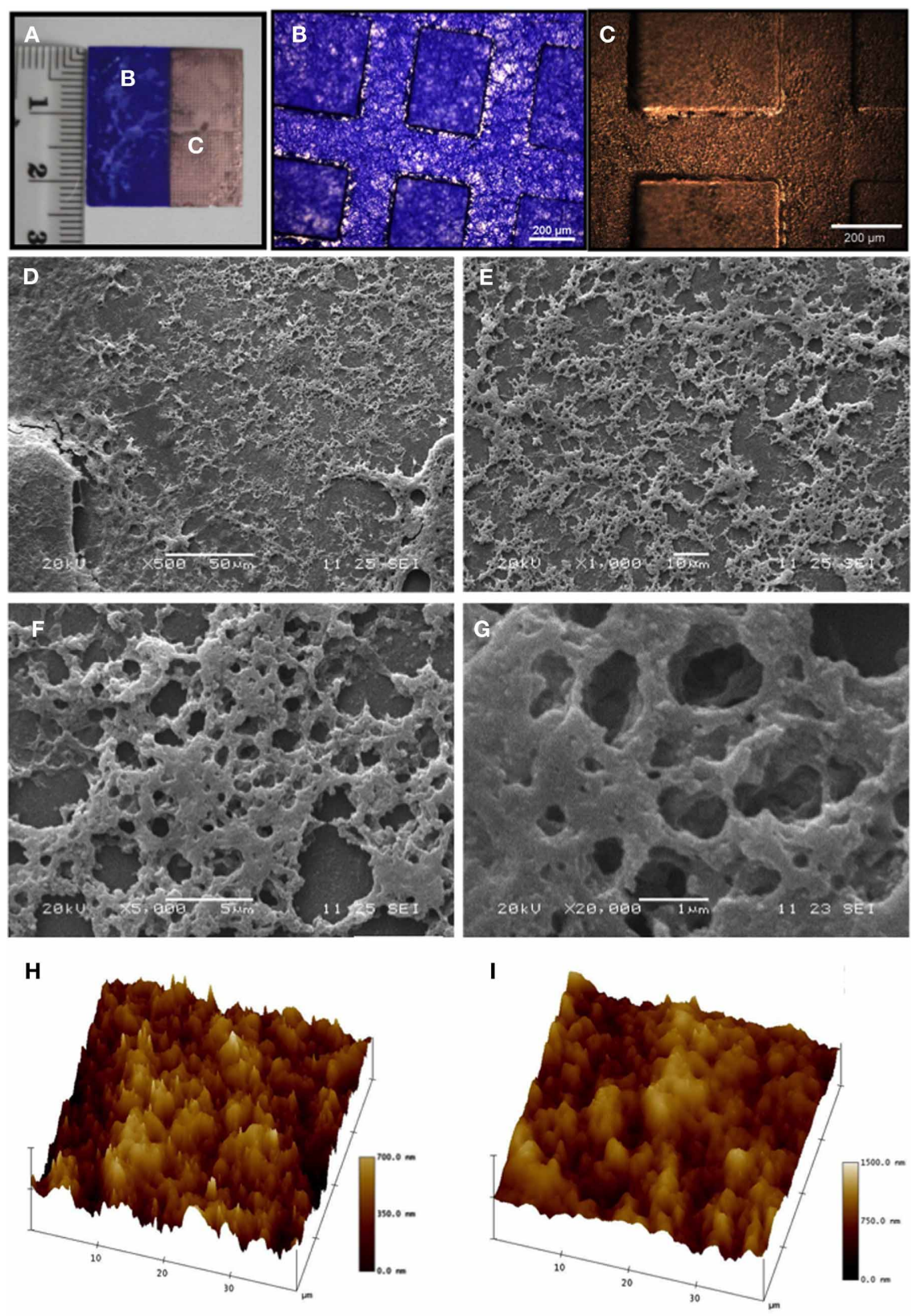

FIGURE 2 | Micro- and nanocharacterization of the neural ECM. (A-C) Before mounting, samples (A) were stained with Coomassie blue (B) and then coated by a thin gold layer (C). (D-G) Matrix characterization by scanning electron microscopy (SEM). At a lower magnification (D, 500x, scale bar $50 \mu \mathrm{m})$, a homogeneous coating of valleys in the patterned substrate may be appreciated. At higher magnifications (E, 1,000x, scale bar $10 \mu \mathrm{m} ; \mathbf{F}, 5,000 \times$,

scale bar $5 \mu \mathrm{m}$; G, 20,000x, scale bar $1 \mu \mathrm{m})$, a fibrous structure with pores of different sizes is evident. (H,I) Atomic force microscopy (AFM) analyses under both $\operatorname{dry}(\mathbf{H})$ and wet $\mathbf{( I )}$ conditions showed that the matrix volume increased with hydration, as expected. Darker areas correspond to lower protein density areas, while lighter areas correspond to higher protein density areas.

Micropatterned coverslips prepared in the absence of neural ECM produced disorganized cell networks that localized over both peaks and valleys (Appendix, Figure A1A). A similar effect was observed with ECM in the absence of micropatterning (Figure A1B). Only the presence of both ECM and surface microgeometry directed PC12 cells to ECM deposits on valleys, where they apparently formed proper neurons (Figure A1C).
To determine the appropriate cell density to achieve an optimal cellular differentiation, different concentrations of PC12 cells were seeded and, after 10 days in vitro, analyzed by silver proteinate staining for detailed observation of the neuritic extensions (Figure 3A). A density range of $40-80$ thousand cells $/ \mathrm{ml}$ was suitable for cell differentiation in these conditions. Morphometric analyses showed that, although maximum neuron numbers were 

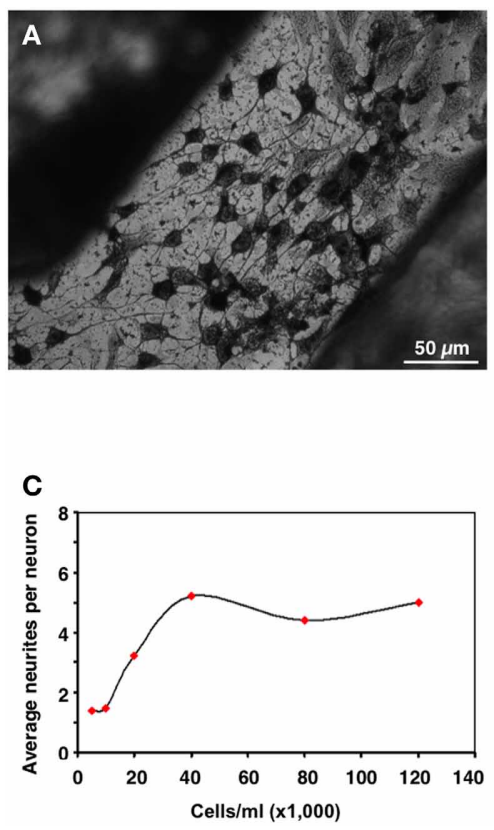

FIGURE 3 | Quantification of neuronal differentiation of PC12 cells on micropatterned substrates. (A) PC12 cells were differentiated for 10 days and stained by Bodian's silver proteinate. Scale bar, $50 \mu \mathrm{m}$. (B) Quantification of the average number of neurons per field of view (approximately $20 \mathrm{~mm}^{2}$ ) as a function of cell density. ${ }^{* *} p=0.0097$.

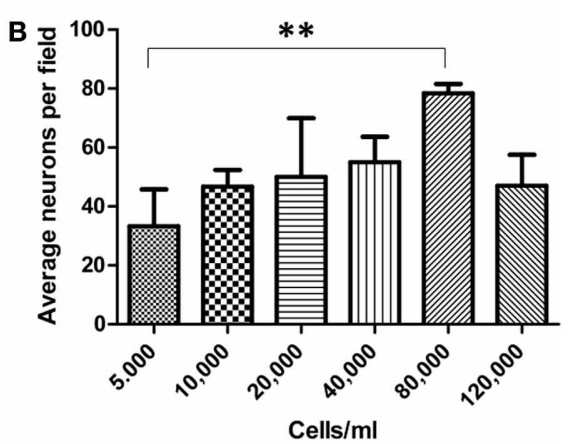

D

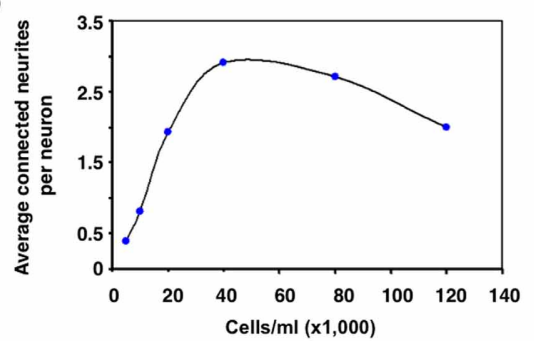

(C) Quantification of the average number of neurites per neuron as a function of cell density. (D) Quantification of the average number of neuritic connections as a function of cell density. At least ten different fields out of three independent experiments were quantified obtained at a density of 80,000 cells/ml (Figure 3B), improved differentiation as shown by the average number of total neurites per neuron (Figure 3C) as well as by their interaction (Figure 3D), peaked at 40,000 cells/ml. For these reasons, a cell seeding density of 40,000 cells/ml was established.

To further characterize the degree of neuronal development and orientation, cells were observed microscopically by histological and immunofluorescent stainings and also scanned at greater detail by SEM (Figure 4). May Grunwald's eosin methylene blue staining showed good interconnection of cells with apparent neuronal morphology (Figure 4A). SEM images confirmed the existence of neuritic extensions that connected the differentiated PC12 cells (Figures 4B-D). Furthermore, differentiated PC12 cells expressed neuronal marker NFL $(95.7 \% \pm 4.2)$ and dopaminergic neuronal marker TH $(84.4 \% \pm 7.5)$ (Figures 4E,F, respectively). Taken together, these results indicated that PC12 cells, differentiated in the absence of NGF, presented an apparently mature neuronal phenotype $\left(\mathrm{TH}^{+}\right.$and thus potentially capable of producing dopamine and norepinephrine).

\section{VALIDATION OF THE SUBSTRATE WITH PRIMARY DERMAL PRECURSOR CELLS}

To validate the neural differentiation potential of the substrate on primary cells, we isolated adult rat SKPs under non-adherent conditions. Rat SKPs grown and expanded for 7 days in vitro formed dermospheres of variable diameters in suspension (Figure 5A). In our hands, $>50 \%$ of dermospheres $(53.4 \pm 13.3 \%)$ presented a diameter of 50-200 $\mathrm{m}$, which was determined as the most appropriate sphere size for differentiation experiments
(Figure 5B and data not shown). Within $24 \mathrm{~h}$, seeded dermospheres attached to the matrix and started their differentiation. After 3 days, colonization of the surrounding matrix by some cells with an apparent neuronal morphology was observed. At day 7 neural networks started to be apparent in the sphere surroundings (Figure 5C), that were later expanded throughout culture substrate (Figure 5D). Neuronal phenotype of these cells was confirmed by Bodian's staining (Figure 5E) (Gambetti et al., 1981). In all cases, neurons differentiated over a "cushion" of apparently undifferentiated cells (Figures 5C-E; blue arrows).

Finally, the neural phenotype of differentiated SKPs was confirmed by staining with anti-Nestin and anti- $\beta$ III-tubulin antibodies. As shown in Figure 6A, Nestin ${ }^{+}$cells $(42.5 \% \pm 3.5 \%)$ presented cytoplasmic projections consistent with an immature neuronal phenotype after 10 days of differentiation. Four days later a remarkable decrease of Nestin $^{+}$cells $(12.5 \% \pm 2.1 \%)$ was detected, which was not further investigated. Concomitantly, Nestin $^{-}$cells overproliferated in the culture. The remaining Nestin $^{+}$cells further matured, as shown by a significant increase in the size of their neuritic extensions (Figure 6B). At day 20 , similar proportions of $\beta$ III-tubulin ${ }^{+}$cells $(7.5 \% \pm 1.9 \%$; Figure 6C) were detected, indicating that $\mathrm{Nestin}^{+}$cells had evolved to cells with an immature neuronal phenotype, that presented long neuritic extensions. As aforementioned, a confluent monolayer of cells undifferentiated to the neural lineage ( $\beta$ III-tubulin $\left.{ }^{-}\right)$was consistently found below immature neurons. These cells were $\alpha-\mathrm{SMA}^{+}$, indicating their myofibroblastic phenotype (Figure 6D). It was not possible to further follow up differentiation since cultures started to degenerate after 20 

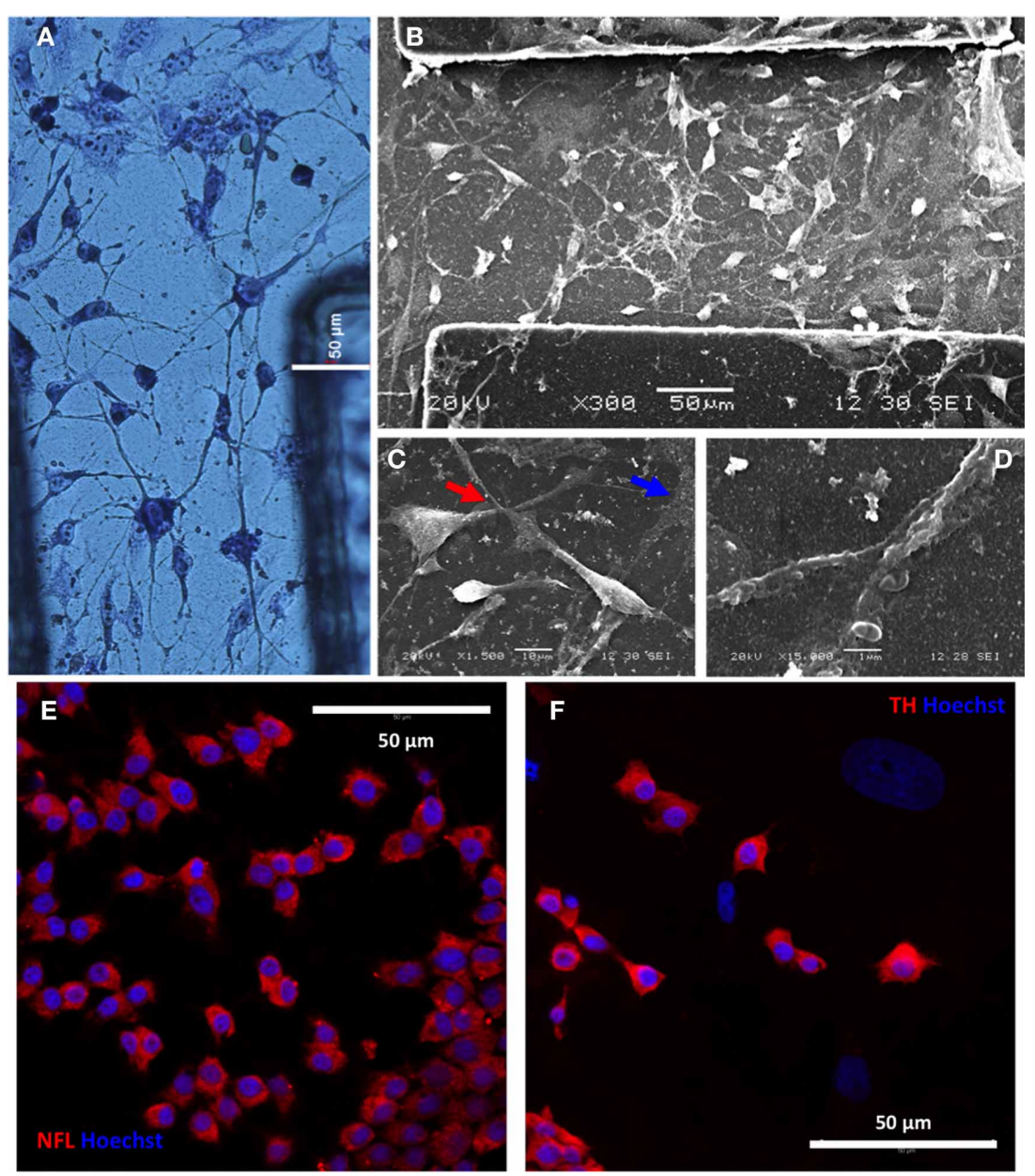

FIGURE 4 | PC12 cells differentiate to interconnected tyrosine hydroxilase (TH)-positive neurons. (A) Differentiated neurons after 10 days differentiation of PC12 cells and staining with May Grunwald's solution. (B-D) Neuronal interconnectivity was appreciated in more detail by SEM (B), showing the emission of neurites from differentiated PC12 cells (C, red arrow) and the contact between them (D). Note the presence of traces of neural extracellular matrix in the preparation (C, blue arrow) after 14 days in vitro. A putative dopaminergic neuronal phenotype was shown by intracellular expression of neurofilament $L$ (NFL; panel $\mathbf{E}$ ) and tyroxine hydroxilase ( $\mathrm{TH}$; panel F) markers, as seen by inmmunofluorescence and confocal microscopy (red). Cell nuclei were counterstained with Hoechst 33258 (blue). days. In summary, neural ECM promoted the differentiation of primary rat SKPs into seemingly immature neurons.

\section{DISCUSSION}

Previous studies on the adhesion, proliferation, orientation, and migration of cells on biocompatible surfaces show that surface microgeometry influences neuronal cell behavior and neuritic outgrowth, i.e., showing improved adhesion of cells to the substrate and growth parallel to the direction of the grooves ( $\mathrm{Lim}$ and Donahue, 2007; Norman et al., 2009; Rao and Winter, 2009). In 1988, Kleinfeld first used photolithographied glass substrates for the culture of dissociated neurons (Kleinfeld et al., 1988). Since then, micropatterned substrates combined with adhesive surface coatings have enabled researchers to precisely control the position and orientation of individual neurons (Chang and Sretavan, 2008). Thus far, simple neural circuits that can be aligned with arrays of microelectrodes have been created, both flat and tridimensional (Francisco et al., 2007; Jaber et al., 2009; Williams, 2009; Carabelli et al., 2010). However, many polymers used in these processes are unsuitable for biological systems. They are not optimized to interact with cells and have neither the composition nor the functionality that would correspond to a true ECM (Delcroix et al., 2010). For these reasons, new scaffolds that combine biodegradable synthetic polymers with components of the natural ECM are needed.

As a first study, we chose relatively wide $(200 \mu \mathrm{m})$ channels to fit a number of cells in parallel since our experimental approach was targeted for neural tissue engineering, not for neural circuits in which narrower channels are more appropriate. In a somewhat related work, Lee et al. showed that human embryonic stem cells seeded onto $350 \mathrm{~nm}$ ridge/groove pattern arrays differentiated into neuronal lineage after 5 days, in the absence differentiation-inducing agents (Lee et al., 2010). We have not thus tested the impact of channel sizing on development and 

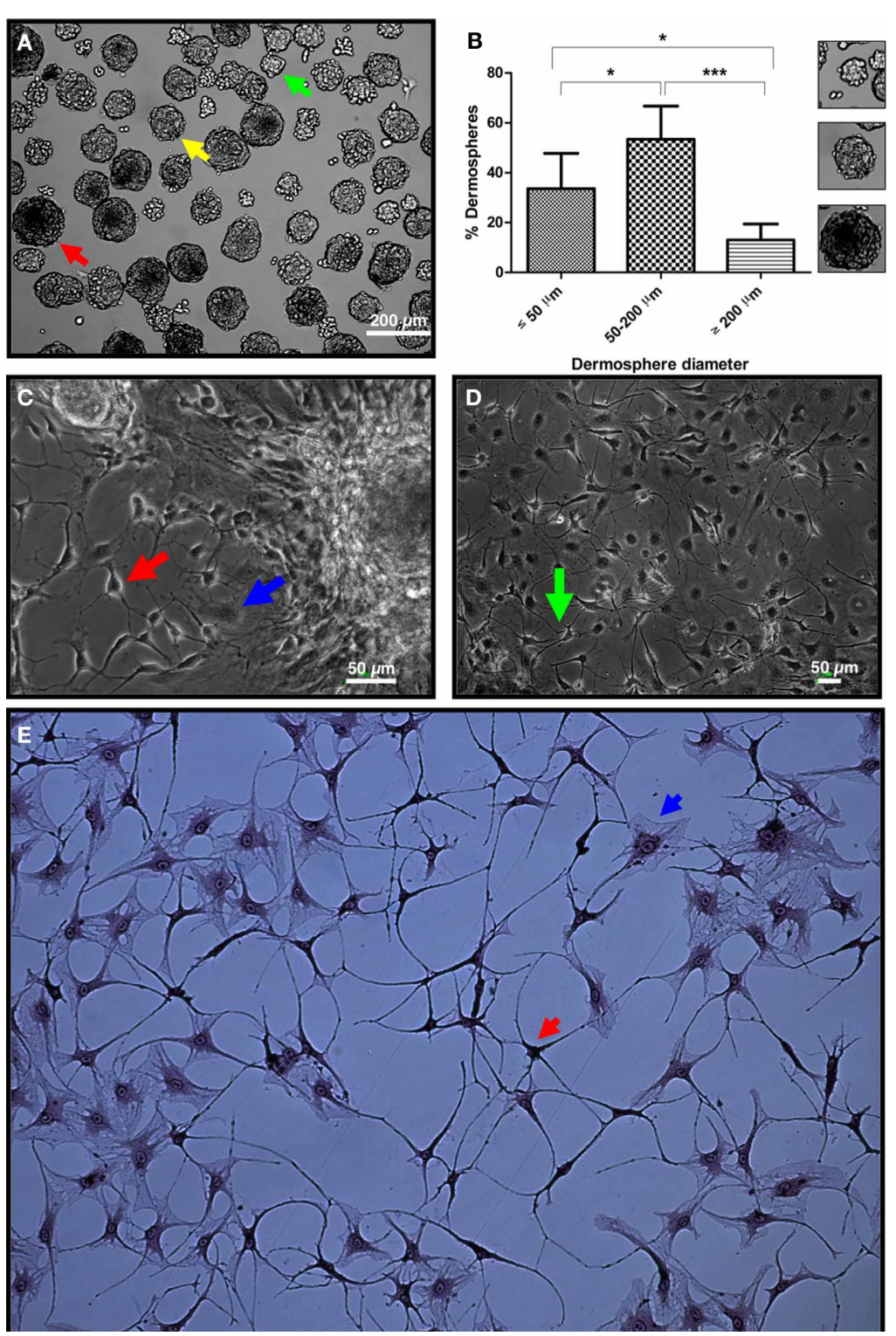

FIGURE 5 | Validation of the micropatterned substrate by neural differentiation of primary SKPs. (A) Dorsal skin dermospheres of small (green arrow), medium (yellow arrow) and large (red arrow) diameter size formed after 7 days in vitro. (B) Quantification of spheres with a diameter size below 50, in between 50 and 200, and over $200 \mu \mathrm{m}$. At least ten different fields out of three independent experiments were quantified. ${ }^{*} p<0.05$; ${ }^{* * *} p<0.001$. Small panels on the right show typical spheres of the three size ranges. (C) Dermospheres collected with a micropipette and seeded onto the developed extracellular matrix in neuronal inducing medium showed apparent neurons with a clear polar morphology and neurite emissions (red arrow), as well as seemingly undifferentiated stromal cells (blue arrow) after 7 days in differentiation conditions. (D) A neuronal network was apparent after 10 days differentiation (green arrow). (E) Neuronal phenotype was confirmed by Bodian's silver proteinate staining (red arrow), although stromal cells non-differentiated to the neural lineage were also seen (blue arrow). differentiation of neuronal cells. However several recent studies have addressed the issue channel size and fiber topography can also play a vital role in regulating differentiation and proliferation of rat hippocampus-derived adult NSCs (rNSCs) on laminincoated electrospun polyethersulfone fibers (Christopherson et al., 2009). For instance Béduer et al. elegantly showed that adult human neural stem cells have a preference for a channel width larger than cell soma diameter when seeded on micropatterned PDMS surfaces (Beduer et al., 2012).
Here we presented a polymeric substrate with two complementary components whose combination is novel: a synthetic surface microgeometry capable of supporting and directing the cells to a coupled differentiation process and a neural ECM formulated with proteins and molecules that induce neuronal differentiation.

With regard to its physical structure, our ECM has an adequate porous fibrosity to accommodate neuronal differentiation, similar to other neural matrices that have used distinct 


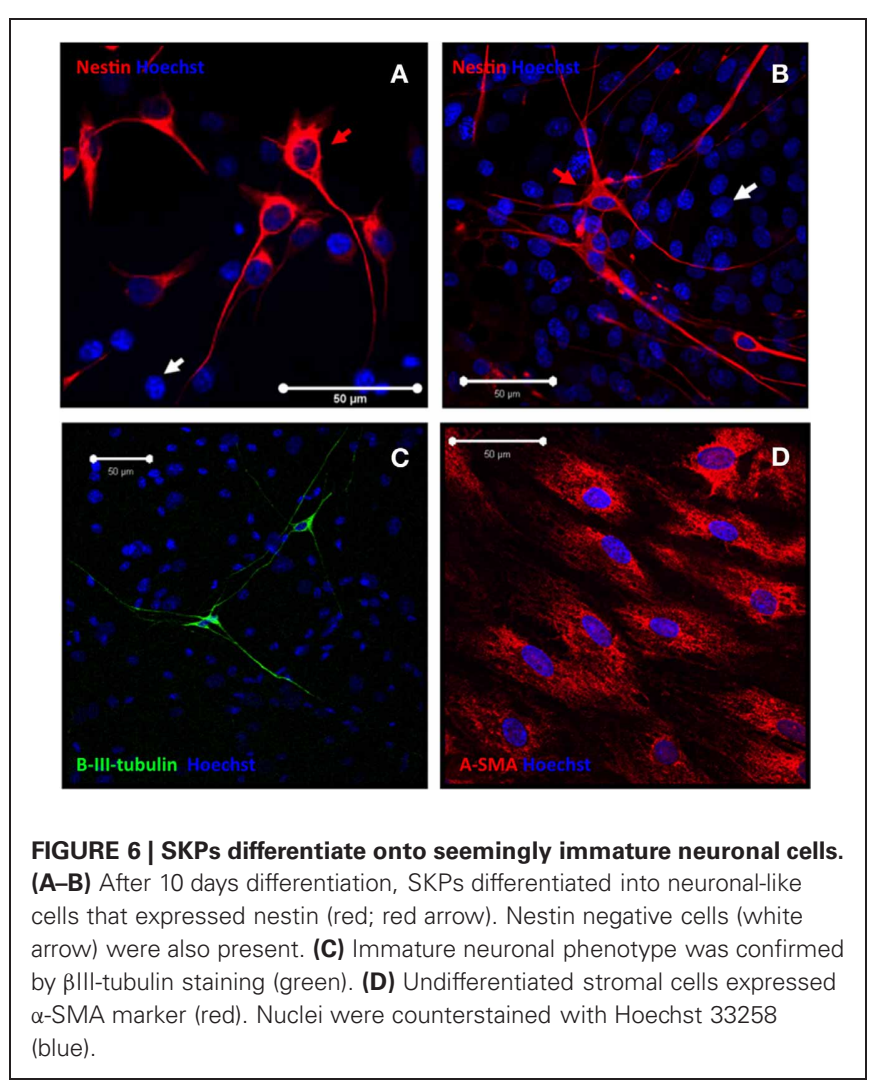

biomaterials and, more importantly, similar to the porosity of the natural rat brain matrix (Bettinger et al., 2009; Christopherson et al., 2009). Of note, our fibrous network tends to increase its volume in culture medium possibly due to hydration capacity provided by the presence of low molecular hyaluronic acid, which will facilitate, in turn, cell movement and neurite extension. However and as a word of caution, it should be noted that while the hyaluronic acid of high molecular weight $(>500 \mathrm{kDa})$ is anti-angiogenic, anti-inflammatory and immunosuppressive, hyaluronic acid of low molecular weight $(10-500 \mathrm{kDa})$ is highly angiogenic and proinflammatory (Csoka et al., 2001; Stern, 2004). In theory, this single fact would prevent further use of the substrate in vivo as formulated, unless rigorous testing shows an appropriate safety profile of the inserted constructs. In any case, the possibility of incorporating biologically active molecules combined with neurotrophic factors into the neural ECM is a promising tool for cell differentiation analyses in vitro. In fact, a reduced concentration of inducer molecules is needed to generate a response when incorporated into ECM as compared to soluble administration (Bhang et al., 2009; Valmikinathan et al., 2009).

Work by others have shown the influence of micro- and nanogeometries (Mahoney et al., 2005; Koh et al., 2008; Cao et al., 2009; Xie et al., 2009; Ferrari et al., 2010), conductive polymers (Green et al., 2009), functional groups (Lamour et al., 2009; Ren et al., 2009), surface-immobilized peptides and molecules (Cooke et al., 2010; Lamour et al., 2010) and cell density (Ruiz et al., 2008) on the differentiation and neurite extension of PC12 cell line and neural stem/progenitor cells. In the present article, we corroborate that substrate microgeometry in combination with the synergistic action of the matrix allows the development of large PC12 networks. However use of continuous cell lines such as PC12 has a relatively little impact on development of tissue engineering products for human use, as compared for instance to rodent and human neural precursor cells.

Foetal, neonatal and adult SKP cells from several species have been previously isolated and characterized by several groups, including our own (Gago et al., 2009). However there is ample room for improvement of current protocols to isolate, enrich, expand, and differentiate these cells into the neural lineage. In the present work, adult SKPs were chosen since their therapeutic application is more obvious. Dermosphere-derived cells expressed Nestin in early stages of differentiation. However, stromal cells (presumably acting as structural and trophic support vehicles to make neurons mature) presented a higher rate of proliferation on the substrate that finally provoked degeneration of differentiation cultures after day 20. This might be the reason why no MAP2/TH positive neurons have been detected from SKPs (data not shown), although other groups also failed to differentiate SKPs into mature neurons in vitro by using more standard culture conditions (Gingras et al., 2007; Fernandes et al., 2008). As an alternative, it will be interesting to explore the differentiation potential of SKPs into cells of the glial lineage such as Schwann cells (Biernaskie et al., 2006; Fernandes et al., 2006; McKenzie et al., 2006) on the newly developed substrates.

The neurons here obtained were characterized by Bodian's method which stains neurofilaments, i.e., neuron-specific cytoplasmic intermediate filament proteins (Gambetti et al., 1981). On the other hand, $\beta$ III tubulin antibody has been widely used in the literature to "specifically" immunostain both neurons and other neural precursor cells. Since SKPs are known to generate both immature neurons and Schwann cells in vitro, we would expect to have more $\beta$ III tubulin ${ }^{+}$cells than Bodian ${ }^{+}$ cells, although the exact relationship between both cell types and concurrent stainings has not been properly addressed in this manuscript. It should also be noted that $\mathrm{TH}+$ neurons are not necessarily dopaminergic (DA) and future studies will analyze other markers such as D2 dopamine receptor or dopamine transporter and the presence of neuronal processes characteristic of DA neurons. Likewise, electrophysiological recordings would best assess functional interconnectivity of the neurons.

In conclusion, a biocompatible micropatterned support with neural-like ECM that can efficiently induce the neural differentiation of precursor cells has been generated. Although we have not investigated the issue in detail, neuronal cells do not seem to sense geometry after a certain maximum channel wideness (about $50 \mu \mathrm{m})$ and apparently recognize big $(>200 \mu \mathrm{m})$ channels as a flat surface (Yang et al., 2005; Solanki et al., 2010). For this reason we believe that matrix components deposited over micropatterned substrates allowed cell adhesion and differentiation into neurons. To our knowledge, the unique combination of proteins, signaling factors and biomaterials presented here represents a major improvement on the neural differentiation of SKPs in vitro. This biomaterial-ECM-cell differentiation system could also be tailored to generate other cell types, and also incorporate additional neural inducing factors that may be released progressively to the medium as desired. In our view, this new $3 \mathrm{D}$ 
culture system will represent a useful tool for modeling the effect of drugs on neural signaling pathways. Usefulness of this differentiation system for the transplantation of in vitro engineered neural tissue will need to be shown through preclinical validation, via in vivo experiments on the relevant animal models of disease.

\section{ACKNOWLEDGMENTS}

We thank Noelia Álvarez for support with animals and Fundación Inbiomed for support with confocal microscopy. This work was financed by a grant from the Department of Industry

\section{REFERENCES}

Arnaoutova, I., George, J., Kleinman, H. K., and Benton, G. (2012). Basement Membrane Matrix (BME) has multiple uses with stem cells. Stem Cell Rev. 8, 163-169.

Beduer, A., Vieu, C., Arnauduc, F., Sol, J. C., Loubinoux, I., and Vaysse, L. (2012). Engineering of adult human neural stem cells differentiation through surface micropatterning. Biomaterials 33, 504-514.

Bettinger, C. J., Bruggeman, J. P., Misra, A., Borenstein, J. T., and Langer, R. (2009). Biocompatibility of biodegradable semiconducting melanin films for nerve tissue engineering. Biomaterials 30, 3050-3057.

Bhang, S. H., Lee, T. J., Lim, J. M., Lim, J. S., Han, A. M., Choi, C. Y., Kwon, Y. H., and Kim, B. S. (2009). The effect of the controlled release of nerve growth factor from collagen gel on the efficiency of neural cell culture. Biomaterials 30, 126-132.

Biernaskie, J. A., McKenzie, I. A., Toma, J. G., and Miller, F. D. (2006). Isolation of skin-derived precursors (SKPs) and differentiation and enrichment of their Schwann cell progeny. Nat. Protoc. 1, 2803-2812.

Blong, C. C., Jeon, C. J., Yeo, J. Y., Ye, E. A., Oh, J., Callahan, J. M., Law, W. D., Mallapragada, S. K., and Sakaguchi, D. S. (2010). Differentiation and behavior of human neural progenitors on micropatterned substrates and in the developing retina. J. Neurosci. Res. 88, 1445-1456.

Cao, H., Liu, T., and Chew, S. Y. (2009). The application of nanofibrous scaffolds in neural tissue engineering. Adv. Drug Deliv. Rev. 61, 1055-1064.

Carabelli, V., Gosso, S., Marcantoni, A., Xu, Y., Colombo, E., Gao, Z., Vittone, E., Kohn, E., Pasquarelli, A., and Carbone, E. (2010). Nanocrystalline diamond microelectrode arrays fabricated on sapphire technology for high-time resolution of quantal catecholamine secretion from chromaffin cells. Biosens. Bioelectron. 26, 92-98.
Chang, W. C., and Sretavan, D. W. (2008). Novel high-resolution micropatterning for neuron culture using polylysine adsorption on a cell repellant, plasmapolymerized background. Langmuir 24, 13048-13057.

Christopherson, G. T., Song, H., and Mao, H. Q. (2009). The influence of fiber diameter of electrospun substrates on neural stem cell differentiation and proliferation. Biomaterials 30, 556-564.

Clarke, J. C., Tuft, B. W., Clinger, J. D., Levine, R., Figueroa, L. S., Guymon, C. A., and Hansen, M. R. (2011). Micropatterned methacrylate polymers direct spiral ganglion neurite and Schwann cell growth. Hear. Res. 278, 96-105.

Cooke, M. J., Zahir, T., Phillips, S. R., Shah, D. S., Athey, D., Lakey, J. H., Shoichet, M. S., and Przyborski, S. A. (2010). Neural differentiation regulated by biomimetic surfaces presenting motifs of extracellular matrix proteins. J. Biomed. Mater. Res. A 93, 824-832.

Corey, J. M., and Feldman, E. L. (2003). Substrate patterning: an emerging technology for the study of neuronal behavior. Exp. Neurol. 184 (Suppl. 1), S89-S96.

Csoka, A. B., Frost, G. I., and Stern, R. (2001). The six hyaluronidaselike genes in the human and mouse genomes. Matrix Biol. 20, 499-508.

Dalton, P. D., and Mey, J. (2009). Neural interactions with materials. Front. Biosci. 14, 769-795.

Das, K. P., Freudenrich, T. M., and Mundy, W. R. (2004). Assessment of PC12 cell differentiation and neurite growth: a comparison of morphological and neurochemical measures. Neurotoxicol. Teratol. 26, 397-406.

Delcroix, G. J., Schiller, P. C., Benoit, J. P., and Montero-Menei, C. N. (2010). Adult cell therapy for brain neuronal damages and the role of tissue engineering. Biomaterials 31, 2105-2120.

Dewitt, D. D., Kaszuba, S. N., Thompson, D. M., and Stegemann,

and Commerce of the Basque Government (PC200829ANEUROPATX, Spain). Patricia García-Parra was first supported by a fellowship from the "Iñaki Goenaga" Technology Centres Foundation (FCT-IG) (Technology Development Grants for Young Scientists, Spain) and then by a postdoctoral contract funded by Ministerio de Ciencia e Innovación (MICINN) [INNPACTO program (IPT-300000-2010-17)]. Ander Izeta was supported by the "Programa I3SNS" (CES09/015) from Instituto de Salud Carlos III and by Osakidetza-Servicio Vasco de Salud (Spain).

J. P. (2009). Collagen I-matrigel scaffolds for enhanced Schwann cell survival and control of threedimensional cell morphology. Tissue Eng. Part A 15, 2785-2793.

Fereol, S., Fodil, R., Barnat, M., Georget, V., Milbreta, U., and Nothias, F. (2011). Micropatterned ECM substrates reveal complementary contribution of low and high affinity ligands to neurite outgrowth. Cytoskeleton (Hoboken) 68, 373-388.

Fernandes, K. J., Kobayashi, N. R., Gallagher, C. J., Barnabe-Heider, F., Aumont, A., Kaplan, D. R., and Miller, F. D. (2006). Analysis of the neurogenic potential of multipotent skin-derived precursors. Exp. Neurol. 201, 32-48.

Fernandes, K. J., Toma, J. G., and Miller, F. D. (2008). Multipotent skin-derived precursors: adult neural crest-related precursors with therapeutic potential. Philos. Trans. R. Soc. Lond. B Biol. Sci. 363, 185-198.

Ferrari, A., Faraci, P., Cecchini, M., and Beltram, F. (2010). The effect of alternative neuronal differentiation pathways on PC12 cell adhesion and neurite alignment to nanogratings. Biomaterials 31, 2565-2573.

Foley, J. D., Grunwald, E. W., Nealey, P. F., and Murphy, C. J. (2005). Cooperative modulation of neuritogenesis by PC12 cells by topography and nerve growth factor. Biomaterials 26, 3639-3644.

Francisco, H., Yellen, B. B., Halverson, D. S., Friedman, G., and Gallo, G. (2007). Regulation of axon guidance and extension by three-dimensional constraints. Biomaterials 28, 3398-3407.

Gago, N., Perez-Lopez, V., Sanz-Jaka, J. P., Cormenzana, P., Eizaguirre, I., Bernad, A., and Izeta, A. (2009). Age-dependent depletion of human skin-derived progenitor cells. Stem Cells 27, 1164-1172.

Gaillard, A., and Jaber, M. (2011). Rewiring the brain with cell transplantation in Parkinson's disease. Trends Neurosci. 34, 124-133.
Gambetti, P., Autilio Gambetti, L., and Papasozomenos, S. C. (1981). Bodian's silver method stains neurofilament polypeptides. Science 213, 1521-1522.

Gingras, M., Champigny, M. F., and Berthod, F. (2007). Differentiation of human adult skin-derived neuronal precursors into mature neurons. J. Cell. Physiol. 210, 498-506.

Green, R. A., Lovell, N. H., and PooleWarren, L. A. (2009). Cell attachment functionality of bioactive conducting polymers for neural interfaces. Biomaterials 30, 3637-3644.

Greene, L. A., and Tischler, A. S. (1976). Establishment of a noradrenergic clonal line of rat adrenal pheochromocytoma cells which respond to nerve growth factor. Proc. Natl. Acad. Sci. U.S.A. 73, 2424-2428.

Hardelauf, H., Sisnaiske, J., TaghipourAnvari, A. A., Jacob, P., Drabiniok, E., Marggraf, U., Frimat, J. P., Hengstler, J. G., Neyer, A., van Thriel, C., and West, J. (2011). High fidelity neuronal networks formed by plasma masking with a bilayer membrane: analysis of neurodegenerative and neuroprotective processes. Lab Chip 11, 2763-2771.

Hellman, A. N., Vahidi, B., Kim, H. J., Mismar, W., Steward, O., Jeon, N. L., and Venugopalan, V. (2010). Examination of axonal injury and regeneration in micropatterned neuronal culture using pulsed laser microbeam dissection. Lab Chip 10, 2083-2092.

Higashida, T., Jitsuki, S., Kubo, A., Mitsushima, D., Kamiya, Y., and Kanno, H. (2010). Skin-derived precursors differentiating into dopaminergic neuronal cells in the brains of Parkinson disease model rats. J. Neurosurg. 113, 648-655.

Hook, A. L., Voelcker, N. H., and Thissen, H. (2009). Patterned and switchable surfaces for biomolecular manipulation. Acta Biomater. 5, 2350-2370.

Hunt, D. P., Jahoda, C., and Chandran, S. (2009). Multipotent skin-derived precursors: from biology to clinical 
translation. Curr. Opin. Biotechnol. 20, 522-530.

Jaber, F. T., Labeed, F. H., and Hughes, M. P. (2009). Action potential recording from dielectrophoretically positioned neurons inside micro-wells of a planar microelectrode array. J. Neurosci. Methods 182, 225-235.

Kleinfeld, D., Kahler, K. H., and Hockberger, P. E. (1988). Controlled outgrowth of dissociated neurons on patterned substrates. J. Neurosci. 8, 4098-4120.

Kleinman, H. K. (2001). Preparation of basement membrane components from EHS tumors. Curr. Protoc. Cell Biol. Chap. 10, Unit 10.2.

Koh, H. S., Yong, T., Chan, C. K., and Ramakrishna, S. (2008). Enhancement of neurite outgrowth using nano-structured scaffolds coupled with laminin. Biomaterials 29, 3574-3582.

Kubo, A., Yoshida, T., Kobayashi, N., Yokoyama, T., Mimura, T., Nishiguchi, T., Higashida, T., Yamamoto, I., and Kanno, H. (2009). Efficient generation of dopamine neuron-like cells from skin-derived precursors with a synthetic peptide derived from von Hippel-Lindau protein. Stem Cells Dev. 18, 1523-1532.

Kunze, A., Giugliano, M., Valero, A., and Renaud, P. (2011). Micropatterning neural cell cultures in 3D with a multi-layered scaffold. Biomaterials 32, 2088-2098.

Lamour, G., Eftekhari-Bafrooei, A., Borguet, E., Soues, S., and Hamraoui, A. (2010). Neuronal adhesion and differentiation driven by nanoscale surface freeenergy gradients. Biomaterials 31 , 3762-3771.

Lamour, G., Journiac, N., Soues, S., Bonneau, S., Nassoy, P., and Hamraoui, A. (2009). Influence of surface energy distribution on neuritogenesis. Colloids Surf. B Biointerfaces 72, 208-218.

Lee, M. R., Kwon, K. W., Jung, H., Kim, H. N., Suh, K. Y., Kim, K., and Kim, K. S. (2010). Direct differentiation of human embryonic stem cells into selective neurons on nanoscale ridge/groove pattern arrays. Biomaterials 31, 4360-4366.

Leipzig, N. D., and Shoichet, M. S. (2009). The effect of substrate stiffness on adult neural stem cell behavior. Biomaterials 30 , 6867-6878.

Li, J., McNally, H., and Shi, R. (2008). Enhanced neurite alignment on micro-patterned poly-L-lactic acid films. J. Biomed. Mater. Res. A 87, 392-404.

Lim, J. Y., and Donahue, H. J. (2007). Cell sensing and response to micro- and nanostructured surfaces produced by chemical and topographic patterning. Tissue Eng. 13, 1879-1891.

Mahoney, M. J., Chen, R. R., Tan, J., and Saltzman, W. M. (2005). The influence of microchannels on neurite growth and architecture. Biomaterials 26, 771-778.

McCormick, A. M., and Leipzig, N. D. (2012). Neural regenerative strategies incorporating biomolecular axon guidance signals. Ann. Biomed. Eng. 40, 578-597.

McKenzie, I. A., Biernaskie, J., Toma, J. G., Midha, R., and Miller, F. D. (2006). Skin-derived precursors generate myelinating Schwann cells for the injured and dysmyelinated nervous system. J. Neurosci. 26, 6651-6660.

Norman, L. L., Stroka, K., and Aranda-Espinoza, H. (2009). Guiding axons in the central nervous system: a tissue engineering approach. Tissue Eng. Part B Rev. 15, 291-305.

O’Donnell, M., Chance, R. K., and Bashaw, G. J. (2009). Axon growth and guidance: receptor regulation and signal transduction. Annu. Rev. Neurosci. 32, 383-412.

Orive, G., Anitua, E., Pedraz, J. L., and Emerich, D. F. (2009). Biomaterials for promoting brain protection, repair and regeneration. Nat. Rev. Neurosci. 10, 682-692.

Pan, L., Ren, Y., Cui, F., and Xu, Q. (2009). Viability and differentiation of neural precursors on hyaluronic acid hydrogel scaffold. J. Neurosci. Res. 87, 3207-3220.

Rajasekharan, S., and Kennedy, T. E. (2009). The netrin protein family. Genome Biol. 10, 239.

Rao, S. S., and Winter, J. O. (2009). Adhesion molecule-modified biomaterials for neural tissue engineering. Front. Neuroeng. 2:doi:10.3389/neuro.16.006.2009

Ren, Y. J., Zhang, H., Huang, H., Wang, X. M., Zhou, Z. Y., Cui, F. Z., and An, Y. H. (2009). In vitro behavior of neural stem cells in response to different chemical functional groups. Biomaterials 30, 1036-1044.

Reynolds, B. A., and Weiss, S. (1992). Generation of neurons and astrocytes from isolated cells of the adult mammalian central nervous system. Science 255, 1707-1710.

Ruiz, A., Buzanska, L., Gilliland, D., Rauscher, H., Sirghi, L., Sobanski,
T., Zychowicz, M., Ceriotti, L., Bretagnol, F., Coecke, S., Colpo, P., and Rossi, F. (2008). Micro-stamped surfaces for the patterned growth of neural stem cells. Biomaterials 29, 4766-4774.

Schenke-Layland, K., Rofail, F., Heydarkhan, S., Gluck, J. M., Ingle, N. P., Angelis, E., Choi, C. H., Maclellan, W. R., Beygui, R. E. Shemin, R. J., and HeydarkhanHagvall, S. (2009). The use of three-dimensional nanostructures to instruct cells to produce extracellular matrix for regenerative medicine strategies. Biomaterials 30, 4665-4675.

Shi, P., Nedelec, S., Wichterle, H., and Kam, L. C. (2010). Combined microfluidics/protein patterning platform for pharmacological interrogation of axon pathfinding. Lab Chip 10, 1005-1010.

Solanki, A., Shah, S., Memoli, K. A., Park, S. Y., Hong, S., and Lee, K. B. (2010). Controlling differentiation of neural stem cells using extracellular matrix protein patterns. Small 6, 2509-2513.

Stern, R. (2004). Hyaluronan catabolism: a new metabolic pathway. Eur. J. Cell Biol. 83, 317-325.

Takahashi, S., Yamazoe, H., Sassa, F., Suzuki, H., and Fukuda, J. (2009). Preparation of coculture system with three extracellular matrices using capillary force lithography and layer-by-layer deposition. J. Biosci. Bioeng. 108, 544-550.

Takayama, Y., Kotake, N., Haga, T., Suzuki, T., and Mabuchi, K. (2011). Microfabrication- and microfluidics-based patterning of cultured neuronal network. Conf. Proc. IEEE Eng. Med. Biol. Soc. 2011, 3613-3616.

Toma, J. G., Akhavan, M., Fernandes, K. J., Barnabe-Heider, F., Sadikot, A., Kaplan, D. R., and Miller, F. D. (2001). Isolation of multipotent adult stem cells from the dermis of mammalian skin. Nat. Cell Biol. 3, 778-784.

Turley, E. A., Noble, P. W., and Bourguignon, L. Y. (2002). Signaling properties of hyaluronan receptors. J. Biol. Chem. 277, 4589-4592.

Uemura, M., Refaat, M. M., Shinoyama, M., Hayashi, H., Hashimoto, N., and Takahashi, J. (2010). Matrigel supports survival and neuronal differentiation of grafted embryonic stem cell-derived neural precursor cells. J. Neurosci. Res. 88, 542-551.
Valmikinathan, C. M., Defroda, S., and Yu, X. (2009). Polycaprolactone and bovine serum albumin based nanofibers for controlled release of nerve growth factor. Biomacromolecules 10, 1084-1089.

Wang, T. W., and Spector, M. (2009). Development of hyaluronic acidbased scaffolds for brain tissue engineering. Acta Biomater. 5, 2371-2384.

Williams, D. F. (2009). On the nature of biomaterials. Biomaterials 30, 5897-5909.

Wissner-Gross, Z. D., Scott, M. A., $\mathrm{Ku}, \mathrm{D}$., Ramaswamy, P., and Fatih Yanik, M. (2011). Large-scale analysis of neurite growth dynamics on micropatterned substrates. Integr. Biol. (Camb.) 3, 65-74.

Xie, J., Willerth, S. M., Li, X., Macewan, M. R., Rader, A., Sakiyama-Elbert, S. E., and Xia, Y. (2009). The differentiation of embryonic stem cells seeded on electrospun nanofibers into neural lineages. Biomaterials 30, 354-362.

Yang, I. H., Co, C. C., and Ho, C. C. (2005). Alteration of human neuroblastoma cell morphology and neurite extension with micropatterns. Biomaterials 26, 6599-6609.

Yang, I. H., Co, C. C., and Ho, C. C. (2011). Controlling neurite outgrowth with patterned substrates. J. Biomed. Mater. Res. A 97, 451-456.

Conflict of Interest Statement: The authors declare that the research was conducted in the absence of any commercial or financial relationships that could be construed as a potential conflict of interest.

Received: 29 December 2011; accepted: 28 February 2012; published online: 14 March 2012.

Citation: García-Parra P, Cavaliere F, Maroto M, Bilbao L, Obieta I, López de Munain A, Álava JI and Izeta A (2012) Modeling neural differentiation on micropatterned substrates coated with neural matrix components. Front. Cell. Neurosci. 6:10. doi: 10.3389/fncel. 2012.00010

Copyright (๑) 2012 García-Parra, Cavaliere, Maroto, Bilbao, Obieta, López de Munain, Álava and Izeta. This is an open-access article distributed under the terms of the Creative Commons Attribution Non Commercial License, which permits non-commercial use, distribution, and reproduction in other forums, provided the original authors and source are credited. 


\section{APPENDIX}

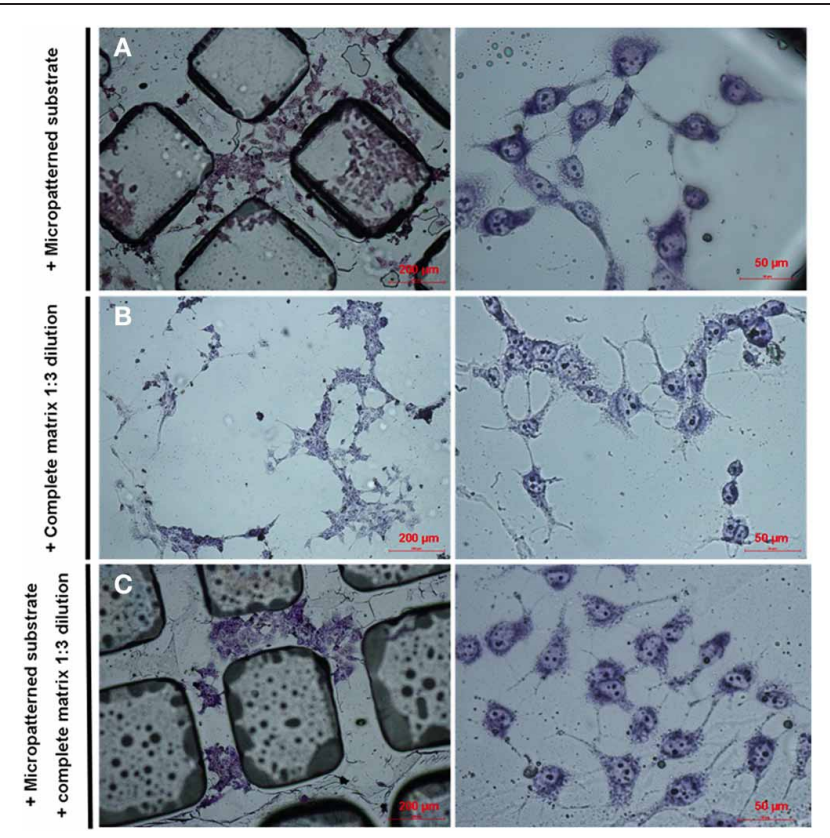

FIGURE A1 | Effects of micropatterned substrate and neural ECM on

PC12 cell differentiation in the absence of NGF. PC12 cells were stained with May Grunwald's eosin methylene blue solution modified for

microscope staining after 7 day-differentiation in vitro. (A) Cells

differentiated in the presence of micropatterned substrate only. (B) Cells

differentiated in the presence of ECM only. (C) Cells differentiated in the

presence of both micropatterned substrate and ECM. 